\title{
Detachment tectonics and hydrothermal circulation pattern beneath TAG, Mid-Atlantic Ridge
}

\author{
LARS RÜPKE ${ }^{1 *}, Z_{\text {HIKUI GUO }}{ }^{1}$, SVEN PETERSEN $^{1}$, CHRIS \\ GERMAN $^{2}$, BENOIT ILDEFONSE ${ }^{3}$, SEBASTIAN FUCHS ${ }^{4}$, \\ JÖRG HASENCLEVER ${ }^{5}$ \\ ${ }^{1}$ Helmholtz Centre for Ocean Research Kiel, Germany, \\ *correspondence: lruepke@geomar.de \\ ${ }^{2}$ Woods Hole Oceanographic Institution, USA \\ ${ }^{3}$ Géosciences Montpellier, University of Montpellier and \\ CNRS, France \\ ${ }^{4}$ BGR Bundesanstalt für Geowissenschaften und Rohstoffe, \\ Germany \\ ${ }^{5}$ Institute of Geophysics, Hamburg University, Germany
}

The TAG hydrothermal mound belongs to the most productive and most comprehensively studied submarine hydrothermal systems and has been drilled during ODP 158 . Over the past 15 years it has become clear that TAG is located on the hanging wall of a detachment fault. This raises important questions about the hydrological regime and the maximum circulation depth of hydrothermal fluids.

Here we combine 3-D hydrothermal flow modeling with 2-D reflection seismic as well as high resolution AUV-based bathymetric data acquired during the 2016 Blue Mining Cruise (M127, Petersen et al., 2016) to evaluate plausible circulation pattern. Our findings challenge the conventional view that hydrothermal upflow is channelized along the detachment from great depth towards the TAG vent field. The bathymetric data rather shows that the TAG mound is located in an area where two sets of N-S vs NE-SW trending fault systems intersect with signs of recent magmatic activity, consistent with a low seismic velocity body previously identified in a P-wave tomography study (Zhao et al., 2012).

Based on these observations, we have constructed a 3-D reactive hydrothermal flow model using OpenFOAM (Guo et al., 2020). We find that a very stable and highly efficient circulation pattern emerges, when upflow within the hanging wall is vertical and focused along the intersecting shallow fault systems. The simulations further show that the precipitation of sulfide minerals and anhydrite around this upflow zone inhibits seawater mixing thereby allowing for efficient metal transport. Segment-scale along-detachment recharge flow, in turn, allows for sustaining the observed high flow rates at TAG. We therefore suggest that hydrothermal circulation is driven by a shallow magmatic intrusion beneath TAG with the detachment fault organizing recharge rather than discharge flow. 